\title{
Loss of Protein Arginine Methyltransferase 8 Alters Synapse Composition and Function, Resulting in Behavioral Defects
}

\author{
Jay Penney, ${ }^{1,2}$ Jinsoo Seo, ${ }^{1,2}$ Oleg Kritskiy, ${ }^{1,2}$-Sara Elmsaouri, ${ }^{1,2}$ Fan Gao, ${ }^{1,2}$-Ping-Chieh Pao, ${ }^{1,2}$ Susan C. Su, ${ }^{1,2}$ \\ and $\oplus_{\text {Li-Huei Tsai }}{ }^{1,2}$ \\ 1Picower Institute for Learning and Memory and 2Department of Brain and Cognitive Sciences, Massachusetts Institute of Technology, Cambridge, \\ Massachusetts 20139
}

\begin{abstract}
Diverse molecular mechanisms regulate synaptic composition and function in the mammalian nervous system. The multifunctional protein arginine methyltransferase 8 (PRMT8) possesses both methyltransferase and phospholipase activities. Here we examine the role of this neuron-specific protein in hippocampal plasticity and cognitive function. PRMT8 protein localizes to synaptic sites, and conditional whole-brain Prmt8 deletion results in altered levels of multiple synaptic proteins in the hippocampus, using both male and female mice. Interestingly, these altered protein levels are due to post-transcriptional mechanisms as the corresponding mRNA levels are unaffected. Strikingly, electrophysiological recordings from hippocampal slices of mice lacking PRMT8 reveal multiple defects in excitatory synaptic function and plasticity. Furthermore, behavioral analyses show that PRMT8 conditional knock-out mice exhibit impaired hippocampal-dependent fear learning. Together, these findings establish PRMT8 as an important component of the molecular machinery required for hippocampal neuronal function.
\end{abstract}

Key words: behavior; excitatory transmission; mouse; plasticity; PRMT8; synaptic proteins

Significance Statement

Numerous molecular processes are critically required for normal brain function. Here we use mice lacking protein arginine methyltransferase 8 (PRMT8) in the brain to examine how loss of this protein affects the structure and function of neurons in the hippocampus. We find that PRMT8 localizes to the sites of communication between neurons. Hippocampal neurons from mice lacking PRMT8 have no detectable structural differences compared with controls; however, multiple aspects of their function are altered. Consistently, we find that mice lacking PRMT8 also exhibit reduced hippocampus-dependent memory. Together, our findings establish important roles for PRMT8 in regulating neuron function and cognition in the mammalian brain.

\section{Introduction}

A myriad of molecular mechanisms regulate synaptic plasticity and cognitive processes in the mammalian brain. The regulation of gene expression, mRNA trafficking to synaptic sites, and numerous post-translational mechanisms, including protein trafficking, phosphorylation, ubiquitination, and acetylation, are all critical to neuronal function (Kandel, 2001). The protein argi-

\footnotetext{
Received March 2, 2017; revised July 6, 2017; accepted July 25, 2017

Author contributions: J.P. and L.-H.T. designed research; J.P., J.S., O.K., S.E., P.-C.P., and S.C.S. performed research; J.P., J.S., O.K., and F.G. analyzed data; J.P. and L.-H.T. wrote the paper.

This work was supported by Robert and Renee Belfer Family Foundation grants to L.-H.T. and a Human Frontier Science Program Long Term Fellowship to J.P. We thank Ashley Waston and Nina Dedic for insightful comments; and Erica McNamara for animal maintenance.

The authors declare no competing financial interests.

Correspondence should be addressed to Dr. Li-Huei Tsai, Picower Institute for Learning and Memory, Department of Brain and Cognitive Sciences, Massachusetts Institute of Technology, 77 Massachusetts Avenue, Cambridge, MA 20139. E-mail: Ihtsai@mit.edu.

DOI:10.1523/JNEUROSCI.0591-17.2017

Copyright $\odot 2017$ the authors $\quad 0270-6474 / 17 / 378655-12 \$ 15.00 / 0$
}

nine methyltransferase (PRMT) family of enzymes regulates multiple cellular processes and pathways; however, the roles of these proteins in brain function have only begun to be explored (Bedford and Clarke, 2009).

PRMT8 is unique among the PRMT proteins in that it is expressed specifically in the nervous system (Lee et al., 2005; Kousaka et al., 2009). Furthermore, PRMT8 is a multifunctional protein, exhibiting both arginine methyltransferase and phospholipase D activities (Lee et al., 2005; Kim et al., 2015). Phospholipase D enzymes play important roles in nervous system development and function, whereas the identification of many arginine-methylated synaptic proteins suggests that this modification may also be an important regulator of synapse biology (Klein, 2005; Burkhardt et al., 2014; Guo et al., 2014). PRMTs, including PRMT8, have been ascribed nuclear roles in regulating gene expression; however, PRMT8 protein can be myristoylated and membrane-targeted, suggesting that it could localize to synaptic sites as well (Lee et al., 2005, 2017; Bedford and Clarke, 2009; Simandi et al., 2015). 
The zebrafish PRMT8 ortholog was found to be important for nervous system development, whereas mouse studies suggest roles for PRMT8 in cerebellar granule neurons, as well as in GABAergic interneurons of the visual cortex (Kim et al., 2015; Lee et al., 2017). Kim et al. (2015) showed that conditional Prmt8 deletion inhibited the arborization of granule cells and reduced acetylcholine levels in the cerebellum. More recently, Lee et al. (2017) found that $\operatorname{Prmt} 8$ mutation affected perineuronal net formation in the visual cortex, as well as visual acuity of mutant mice. Thus far, the potential effects of PRMT8 on synaptic function and cognitive processes have not been explored.

Here, we examine the roles of PRMT8 in hippocampal neuronal morphology, composition, and function. We find that PRMT8 protein localizes to presynaptic and postsynaptic sites but that loss of PRMT8 does not affect synapse density, or dendritic spine density or morphology. PRMT8 conditional deletion with Nestin-cre does, however, alter levels of a number of synaptic proteins and affect multiple measures of synaptic function and plasticity. Further, whereas PRMT8 mutation does not significantly alter locomotor or anxiety-related behaviors, context-dependent fear learning is impaired in Prmt8 conditional knock-out mice. Together, these findings establish novel roles for PRMT8 in regulating excitatory synapse composition and function as well as cognitive processes in the mammalian nervous system.

\section{Materials and Methods}

Mice. All experiments were performed according to the Guide for the care and use of laboratory animals and were approved by the National Institutes of Health and the Committee on Animal Care at the Massachusetts Institute of Technology. Prmts ${ }^{\text {tmla(EUCOMM)Wtsi }}$ (Skarnes et al., 2011) embryos were obtained from the European Mutant Mouse Consortium. Following rederivation, the mice were crossed to FLP recombinaseexpressing mice (Vooijs et al., 1998) to generate mice with the Prmt 8 fifth exon flanked by loxP sites. Following intercrosses to generate homozygous Prmt8 floxed mice, they were bred to Nestin-cre-expressing mice (Tronche et al., 1999) to conditionally delete Prmt8 exon 5. Prmt8 floxed/ Prmt8 floxed mice served as controls, whereas experimental mice were Prmt8 floxed/Prmt8 floxed; Nestin-cre/+ (referred to as Prmt8 cKO). Ten- to 14-week-old mice were used for all experiments, except for miniature IPSC (mIPSC) and GluN2A-mediated recordings. Mice for these latter experiments were 16-18 weeks old. Male mice were used for immunostaining, Golgi staining, electrophysiology, and behavior experiments. Both male and female mice were used for qPCR and biochemistry experiments.

Primary neuronal culture. Primary forebrain neurons were cultured from E16.5 Swiss Webster embryos and analyzed at DIV17. Briefly, forebrains were removed, digested with papain, and plated on poly-D-lysine (Sigma)-coated glass coverslips for immunostaining (100,000 cells per well in 24-well plates) or poly-D-lysine-coated tissue-culture plates (3 million cells per $10 \mathrm{~cm}$ plate) for cell fractionation experiments.

Cloning. The Prmt8 transcript was amplified from mouse hippocampal cDNA using the primers: forward, 5'-TGCTCTAGAGCAGAAGT TGGGAGAGTTGC-3'; and reverse, 5'-AGAGCGATCGCACGCATT TTGTAGTCATT-3'. The amplified region spanned from base pairs 291594 of the Prmt8 transcript (NM_201371.2), including the coding sequence and most of the $5^{\prime} \mathrm{UTR}$ (to mimic in vivo start codon selection to the extent possible). The Prmt 8 PCR product was digested and cloned into a derivative of the FUGW lentiviral plasmid (Lois et al., 2002) upstream of, and in frame with, $3 \times$ FLAG and $2 \times$ HA tags.

Bioinformatics. The dataset of gene expression from sorted cortical excitatory (pyramidal) and inhibitory (vasoactive intestinal peptide and parvalbumin positive) neurons was from GSE63137. For RNA-Seq data, single-end sequencing reads were mapped to the mouse genome with GENCODE vM9 using STAR. Processed RNA-seq data are available at http://bioinfo5pilm46.mit.edu:318/neugene/.
Immunostaining and imaging. Primary neurons grown on coverslips were transduced with PRMT8-expressing lentivirus at DIV5. At DIV17, the cells were fixed 10 min with $4 \%$ formaldehyde in $1 \times$ PBS, washed with PBS, and blocked $1 \mathrm{~h}$ with blocking buffer (5\% donkey serum, $0.3 \%$ Triton X-100 in PBS), then stained overnight at $4^{\circ} \mathrm{C}$ with primary antibodies in blocking buffer. Primary antibodies used were mouse-PSD95 (NeuroMab) and rabbit-FLAG (Santa Cruz Biotechnology). Primary antibodies were detected using fluorescently conjugated secondary antibodies from Jackson ImmunoResearch Laboratories (anti-mouse-Cy2 and anti-rabbit-Cy5). For brain slices, mice were perfused briefly with PBS, followed by perfusion with $4 \%$ formaldehyde in PBS. Brains were removed and postfixed in $4 \%$ formaldehyde in PBS overnight at $4^{\circ} \mathrm{C}$ followed by storage at $4^{\circ} \mathrm{C}$ in PBS. The $40 \mu \mathrm{m}$ coronal sections were generated with a Leica VT1000S vibratome. Staining was performed as described above for primary neurons. Primary antibodies used were mouse-Svp38 (Sigma) and rabbit-TBR1 (Abcam). Hoechst nuclear stain was added during secondary staining together with anti-mouse-Cy2 and anti-rabbit-Cy3 (Jackson ImmunoResearch Laboratories). Golgi staining was performed with the FD Rapid GolgiStain Kit (Neurotechnologies) following the manufacturer's instructions. Imaging was performed using a 710 confocal microscope (Carl Zeiss).

Western blotting. Western blots were performed using PVDF membranes (Millipore) following standard methods. DIV17 primary neurons infected with PRMT8 lentivirus were used to examine PRMT8 subcellular localization. Cellular fractionation was performed following published protocols with some modifications (Chao et al., 2013). The "presynaptic" fraction is Svp38-enriched, whereas the "postsynaptic" fraction is PSD95-enriched. "Synaptosomal" preparations from mouse hippocampi followed the same procedure and corresponded to the combined presynaptic plus postsynaptic fractions. Antibodies used included the following: mouse-PSD95 (NeuroMAB), mouse-HDAC2 (Abcam), rabbit-HA (Santa Cruz Biotechnology), mouse-Svp38 (Sigma), rabbitCacna1C (Novus), mouse-Syn1 (Synaptic Systems), rabbit-Nsf-1 (Thermo Fisher), rabbit-Syn2 (Abcam), rabbit-Syn3 (Synaptic Systems), rabbitSyt7 (Abcam), mouse-Syt12 (NeuroMAB), rabbit-Cplx1 (Proteintech), mouse- $\beta$-actin (Sigma), rabbit-NR2A (Cell Signaling Technology), rabbit-NR2B (Cell Signaling Technology), mouse-NR1 (Millipore), mouse-GluA1 (Millipore), rabbit-GluA2 (Cell Signaling Technology), mouse-CaMKIIA (Millipore Bioscience Research Reagents), mouse-Shank1 (NeuroMAB), mouse- $\alpha$-tubulin (Sigma), rabbit-Homer (GeneTex), rabbit-eIF4G1 (Cell Signaling Technology), rabbit-eIF4H (Cell Signaling Technology), rabbit-eIF4E (Cell Signaling Technology), and rabbitFMRP (Cell Signaling Technology).

$q P C R$. RNA was extracted from freshly dissected hippocampi using the QIAGEN RNeasy Plus Mini Kit. cDNA synthesis was performed with RNA to cDNA EcoDry Premix (Oligo dT) (Clontech). qPCR was performed with SsoFast EvaGreen Supermix (Bio-Rad) using a C1000 Thermal Cycler and a C96 Real-Time System (Bio-Rad). Target genes were normalized using Histone H2A unless indicated.

Electrophysiology. Transverse hippocampal slices were prepared from 2- to 4-month-old male littermates. The brain was rapidly isolated and transferred to ice-cold, oxygenated $\left(95 \% \mathrm{O}_{2}\right.$ and $\left.5 \% \mathrm{CO}_{2}\right)$ cutting solution containing the following (in mM): 211 sucrose, $3.3 \mathrm{KCl}, 1.3 \mathrm{NaH}_{2} \mathrm{PO}_{4}, 0.5$ $\mathrm{CaCl}_{2}, 10 \mathrm{MgCl}_{2}, 26 \mathrm{NaHCO}_{3}$, and 11 glucose. Hippocampal tissue was cut with a VT1000S vibratome (Leica), and slices were transferred for recovery to a holding chamber containing oxygenated $\left(95 \% \mathrm{O}_{2}\right.$ and $\left.5 \% \mathrm{CO}_{2}\right)$ ACSF consisting of the following (in $\mathrm{mm}$ ): $124 \mathrm{NaCl}, 3.3 \mathrm{KCl}, 1.3$ $\mathrm{NaH}_{2} \mathrm{PO}_{4}, 2.5 \mathrm{CaCl}_{2}, 1.5 \mathrm{MgCl}_{2}, 26 \mathrm{NaHCO}_{3}$, and 11 glucose at $28^{\circ} \mathrm{C}-$ $30^{\circ} \mathrm{C}$ for $1 \mathrm{~h}$ before recording. CA1 field EPSPs (fEPSPs) evoked by Schaffer collateral stimulation were recorded using an AM-1800 Microelectrode amplifier (A-M Systems) with Digidata 1440A A-D converter (Molecular Devices). LTP was induced by three episodes of theta-burst stimulation (TBS) with $10 \mathrm{~s}$ intervals. TBS consisted of 10 brief bursts of stimuli delivered at $5 \mathrm{~Hz}$; each burst contains four pulses at $100 \mathrm{~Hz}$. Whole-cell recordings were performed in CA1 pyramidal neurons as previously described (Seo et al., 2014). In brief, cells were held at $-70 \mathrm{mV}$ with recording pipettes containing the following (in $\mathrm{mm}$ ): $145 \mathrm{CsCl}$, $5 \mathrm{NaCl}, 10$ HEPES-CsOH, 10 EGTA, 4 MgATP, and $0.3 \mathrm{Na}_{2}$ GTP. TTX $(1 \mu \mathrm{M})$ and picrotoxin $(50 \mu \mathrm{M})$ were added to ACSF for miniature EPSC 
A

\begin{tabular}{l|c|c|c}
\hline Protein & MW & \# Unique Pep. & Total Intensity \\
\hline CaMKIIA & 55 & 32 & $6.5 \mathrm{e} 10$ \\
\hline Syn1 & 74 & 34 & $2.1 \mathrm{e} 10$ \\
\hline PSD95 & 95 & 39 & $1.4 \mathrm{e} 10$ \\
\hline Shank1 & 225 & 74 & $4.6 \mathrm{e} 9$ \\
\hline GluA1 & 102 & 68 & $1.6 \mathrm{e} 9$ \\
\hline Syt7 & 51 & 14 & $4.2 \mathrm{e} 8$ \\
\hline Arc & 45 & 15 & $9.9 \mathrm{e} 7$ \\
\hline FMRP & 71 & 6 & $4.2 \mathrm{e} 7$ \\
\hline PRMT1 & 43 & 7 & $1.5 \mathrm{e} 7$ \\
\hline PRMT5 & 73 & 2 & $7.9 \mathrm{e} 5$ \\
\hline PRMT8 & 45 & 16 & $1.3 \mathrm{e} 8$ \\
\hline
\end{tabular}

B

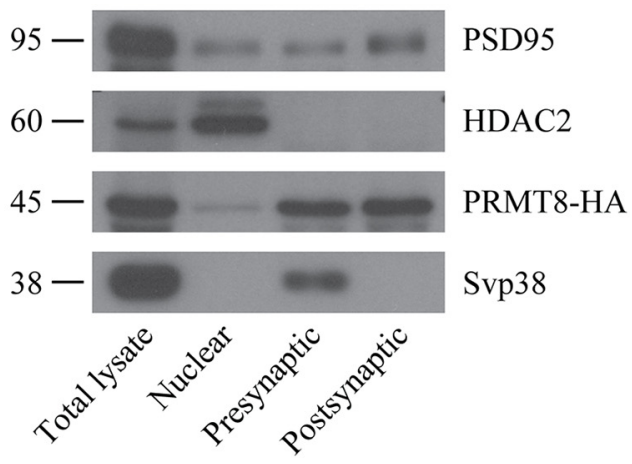

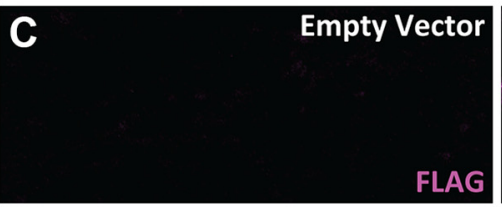
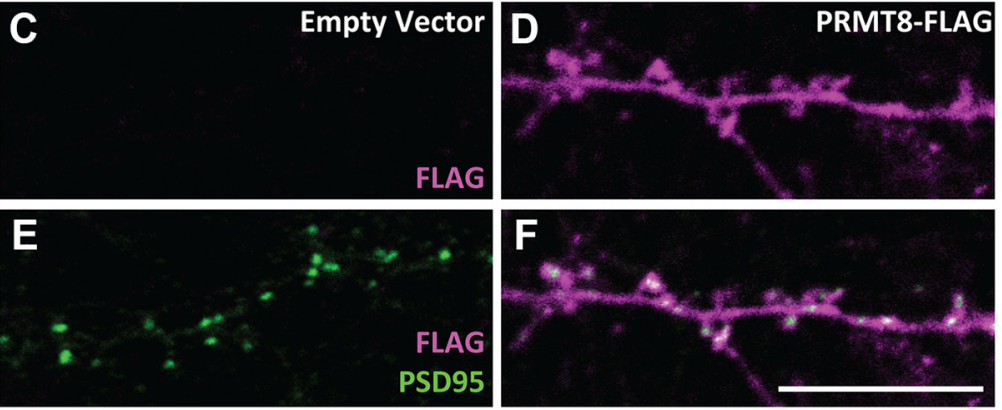

Figure 1. PRMT8 localizes to synaptic sites. $A$, Selected proteins from mass spectrometry analysis of the synaptosomal proteome of wild-type mouse cortex. The names, molecular weight (MW), number of unique peptides identified, and total intensity are indicated. $\boldsymbol{B}$, Western blot of nuclear, presynaptic and postsynaptic density (PSD) fractions from DIV17 mouse primary neurons expressing tagged PRMT8 probed with antibodies recognizing the PSD protein PSD95, the nuclear protein HDAC2, and the synaptic vesicle protein Svp38, as well as HA to detect PRMT8. Equivalent cellular proportions of each fraction were loaded for direct comparison between the fractions. Molecular weights are indicated. $\mathbf{C}-\boldsymbol{F}$, Immunostaining of DIV17 mouse primary neurons expressing tagged PRMT8 and stained with antibodies against FLAG and the postsynaptic marker PSD95. Neurons expressing an empty vector act as a control for the specificity of FLAG staining. Scale bar, $10 \mu \mathrm{m}$.

(mEPSC) measurements, and picrotoxin was replaced with CNQX $(10 \mu \mathrm{M})$ and D-APV $(50 \mu \mathrm{M})$ for mIPSC measurements. For recording GluN2A-containing NMDAR-mediated current, Schaffer collateral was stimulated and recording was performed in CA1 pyramidal neurons. Cells were held at $40 \mathrm{mV}$, and glycine $(10 \mu \mathrm{M})$, picrotoxin $(50 \mu \mathrm{M})$, CNQX $(10 \mu \mathrm{M})$, and Ro 25-6981 (1 $\mu \mathrm{M})$ were added to ACSF to isolate GluN2A-containing NMDAR-mediated current. The decay weighted time constant was calculated as previously reported (Cathala et al., 2005). Recording was performed using a MultiClamp 700B amplifier and a Digidata 1440A A-D converter (Molecular Devices). All data were analyzed by the use of pClamp 10 software (Molecular Devices).

Behavior. Open Field Test: Locomotor activity in an open field arena $(41 \mathrm{~cm} \times 40 \mathrm{~cm} \times 30 \mathrm{~cm})$ was measured over a 10 min period with AccuScan Instruments VersaMax Animal Activity Monitoring System. Time spent in center, total distance, and hyperactivity were measured using the automated monitoring system. Light-Dark Exploration Test: A testing box $(41 \mathrm{~cm} \times 41 \mathrm{~cm} \times 30 \mathrm{~cm})$ was divided into two sections of equal size with a partition that allowed for free movement from one side to the other side. One chamber was brightly illuminated, whereas the other chamber was dark. Mice were placed into the dark side, and measurements were taken for latency to enter the light side, total number of transitions, and total amount of time in the light chamber. Fear Conditioning Test: Mice were put in the conditioning chamber (TSE Systems) for $3 \mathrm{~min}$, followed by a $30 \mathrm{~s}$ auditory cue $(3 \mathrm{kHz}, 80 \mathrm{~dB})$ after which a constant $2 \mathrm{~s}$ foot shock $(0.8 \mathrm{~mA})$ was applied; $24 \mathrm{~h}$ later, mice were reexposed to the training context for $3 \mathrm{~min}$ and their freezing behavior was scored for contextual memory acquisition. At $48 \mathrm{~h}$ after the initial conditioning (training), mice were exposed to a novel context during which they were habituated to the novel context for $2 \mathrm{~min}$, followed by a 2 min auditory cue $(3 \mathrm{kHz}, 80 \mathrm{~dB})$ identical to that from training session, and their freezing behavior was scored for cued memory acquisition.
Experimental design and statistical analysis. Data are mean \pm SEM or percentage and were analyzed by Excel software (Microsoft). Student's $t$ test was used to analyze the means, and $p \leq 0.05$ was considered significant.

\section{Results}

\section{PRMT8 is a synaptic protein}

During mass spectrometry-based proteomic experiments using mouse brain tissue (Su et al., 2012), we noted that several members of the PRMT protein family were found in synaptosomal preparations from wild-type mouse cortex (Fig. 1A). Among these, PRMT8 was most enriched, showing similar abundance to a number of well-established synaptic proteins (Fig. $1 A$ ). Combined with the observation that many synaptic proteins are arginine methylated (Guo et al., 2014), these findings prompted us to examine a role for PRMT8 in regulating synaptic function in more detail. The synaptosomal preparations used for proteomic screening contain both presynaptic and postsynaptic membrane; we thus sought to test whether PRMT8 localizes specifically to one compartment or the other (or both). Available PRMT8 antibodies do not show a specific signal by Western blot or immunostaining (data not shown), so we generated a lentiviral construct to express PRMT8 C-terminally tagged with FLAG and HA (see Materials and Methods). Following expression of this construct in mouse primary neurons, we performed subcellular fractionation to isolate nuclear, presynaptic and postsynaptic enriched fractions (Fig. 1B). These experiments revealed that tagged PRMT8 is enriched in both presynaptic and postsynaptic frac- 
tions, and somewhat surprisingly that PRMT8 is depleted in nuclear fractions (Fig. 1B). We next performed immunostaining to examine the synaptic localization of PRMT8 using mouse primary neurons expressing tagged PRMT8. Consistent with our proteomic and subcellular fractionation findings, PRMT8 signal appeared enriched in dendritic processes and colocalized with PSD95 in dendritic spines (Fig. 1C-F). As in our subcellular fractionation experiments, we did not observe strong PRMT8 signal in neuronal nuclei (data not shown). Together, these findings indicate that PRMT8 protein robustly localizes to both presynaptic and postsynaptic sites, and is less enriched in neuronal nuclei.

\section{Prmt8 cKO mice develop normally}

Having established that PRMT8 is a synaptic protein, we set out to characterize the effects of PRMT8 loss on brain development and function. PRMT8 is widely expressed in mouse neurons; we thus bred mice with the Prmt8 fifth exon flanked by loxP sites (Taneda et al., 2007; Allen Institute, 2011; Skarnes et al., 2011) (Fig. 2A), to mice harboring a Nestin-cre transgene. The Prmt8 fifth exon encodes residues essential for methyltransferase activity, whereas the Prmt8 third exon contains residues required for phospholipase activity (Lee et al., 2005; Kim et al., 2015). qPCR experiments using hippocampal RNA from control (Prmt8 floxed) and Prmt $8 \mathrm{cKO}$ (Prmt8 floxed; Nestin-cre) mice revealed a complete loss of Prmt8 exon 5, as well as strong reductions in full-length Prmt8 transcript, presumably due to nonsensemediated decay (Fig. 2B). Thus, Prmt8 cKO mice lack PRMT8 methyltransferase function and should exhibit strongly reduced phospholipase activity. We next tested whether there might be compensatory changes in the expression of other genes encoding PRMT family members in Prmt $8 \mathrm{cKO}$ mice. qPCR using hippocampal RNA revealed no significant differences in expression of any PRMT family members (aside from Prmt 8 ) in cKO mice compared with controls, suggesting a lack of compensatory changes in response to Prmt8 mutation (Fig. 2C).

Prmt $8 \mathrm{cKO}$ mice were viable and fertile, and brain weights of male and female mice did not differ between cKO and controls (Fig. 2D,E). Similarly, we found no significant difference in cortical thickness between the two groups of mice (Fig. $2 F-L$ ). Immunostaining for the deep layer cortical marker TBR1 (T-box, brain 1) also revealed no difference in the thickness of the TBR1 layer (control: $194 \pm 13 \mu \mathrm{m}$; cKO: $174 \pm 4 \mu \mathrm{m} ; N=9$ for each; Fig. $2 \mathrm{~F}-\mathrm{K}$ ), suggesting that Prmt8 mutation does not affect gross cortical development. We next examined hippocampal structures in Prmt $8 \mathrm{cKO}$ mice and controls, finding that hippocampal thickness in area CA1 did not differ between cKO and control mice (Fig. 2M-S). We next evaluated hippocampal synapse density by immunostaining for the synaptic vesicle protein synaptophysin (Svp38), again finding no difference between cKO and control mice (Fig. $2 M-R, T$ ). To more closely examine neuronal morphology, we performed Golgi staining on brain slices from cKO and control mice. Quantification of dendritic spines on pyramidal neurons revealed no difference in total spine density in control versus cKO mice (Fig. $2 U-W$ ). Similarly, an analysis of dendritic spine morphologies revealed no significant differences in the proportion of "mushroom," "thin," or "stubby" spines between Prmt8 cKO and control mice (Fig. $2 U-X$ ). Together, these findings indicate that neither overall forebrain development nor hippocampal synapse density or dendritic spine morphology is altered by Prmt8 mutation.

\section{Prmt8 mutation alters synaptic function and plasticity}

We next sought to examine whether Prmt8 mutation affects neuronal function and/or synaptic plasticity in the hippocampus. To test this possibility, we performed field potential recordings from area CA1 of hippocampal slices from Prmt $8 \mathrm{cKO}$ mice and controls. Input-output curves generated following stimulation of Schaffer collaterals revealed an increased fEPSP slope in slices from $\mathrm{Prm} t 8 \mathrm{cKO}$ mice, indicating an increase in baseline synaptic transmission (Fig. 3A,B). We next measured the paired-pulse facilitation $(\mathrm{PPF})$ ratio at Schaffer collateral-CA1 synapses, finding that Prmt $8 \mathrm{cKO}$ slices exhibited a reduced PPF ratio (Fig. $3 C$ ). This reduced PPF ratio suggests that $\mathrm{Prm} t 8$ mutation results in an increased probability of presynaptic neurotransmitter release. We then tested whether LTP of Schaffer collateral-CA1 synapses was altered by Prmt 8 mutation. We found that, although $3 \times$ TBS (theta-burst stimulation) did induce LTP in slices from Prmt8 cKO mice, its magnitude was significantly reduced compared with control slices (Fig. 3D,E). Thus, Prmt8 mutation appears to increase evoked neurotransmitter release at Schaffer collateralCA1 synapses while also reducing long-term synaptic plasticity induced by TBS.

We next sought to test whether miniature synaptic transmission was affected by Prmt 8 mutation. We first verified that Prmt8 was expressed in both excitatory and inhibitory neurons in vivo using publicly available cell type-specific gene expression data (Mo et al., 2015) (also available at http://bioinfo5pilm46.mit. edu:318/neugene/). Although these data showed strong expression of Rbfox3 (encoding NeuN) in both excitatory and inhibitory neurons, and the expected enrichments of Slc17a7 (encoding VGlut1) and Gad1 (encoding Gad67) in excitatory or inhibitory neurons, respectively, we found that Prmt8 expression was almost identical in the two neuronal subtypes (Fig. $4 A-D$ ).

Thus, we proceeded to perform intracellular recordings from CA1 pyramidal neurons to measure spontaneous mEPSCs. Typically, changes in MEPSC frequency are taken to reflect differences in synapse number and/or probability of presynaptic release, whereas altered mEPSC amplitudes are most often due to altered postsynaptic neurotransmitter receptor levels or function. Our analysis of intracellular recordings in $\mathrm{Prmt} 8 \mathrm{cKO}$ versus control slices revealed a significant $\sim 15 \%$ increase in mEPSC amplitudes, as well as a more than tripling of mEPSC frequency in neurons lacking functional PRMT8 (Fig. 4E-I). This large increase in $\mathrm{mEPSC}$ frequency was surprising considering we did not observe any differences in synaptophysin staining intensity (Fig. $2 M-T$ ) or dendritic spine density (Fig. $2 U-X$ ), although it is consistent with the increased baseline transmission and reduced PPF values we observed in Prmt 8 cKO mice. Thus, the elevated mEPSC frequency may reflect an alteration in synaptic vesicle dynamics or recycling, resulting in an increase in presynaptic neurotransmitter release. Regardless, these findings indicate that Prmt8 cKO mice exhibit considerable defects affecting both presynaptic and postsynaptic excitatory neuronal function and plasticity.

We next measured spontaneous mIPSCs from CA1 pyramidal neurons. In contrast to the striking alterations in MEPSC amplitude and frequency we observed, we found no significant differences in mIPSC amplitude or frequency when comparing slices from control and Prmt $8 \mathrm{cKO}$ mice (Fig. $4 J-N$ ). Thus, despite the reported defects in inhibitory neuron structures in the visual cortex (Lee et al., 2017), and the differences in excitatory synaptic function just described, we did not detect any alterations due to Prmt8 mutation in miniature inhibitory currents received by hippocampal pyramidal neurons. 


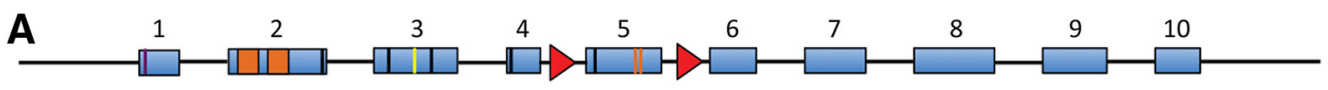

| N-myristoyl $\square$ SH3-binding ISAM-binding | Phospholipase critical residue | Methyltransferase active site $D$ loxP

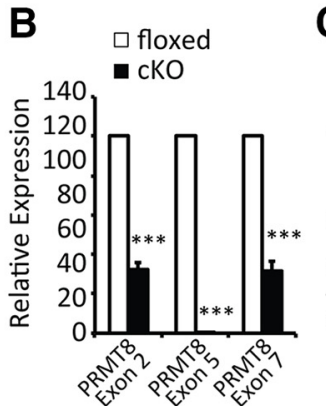

C $\square$ floxed
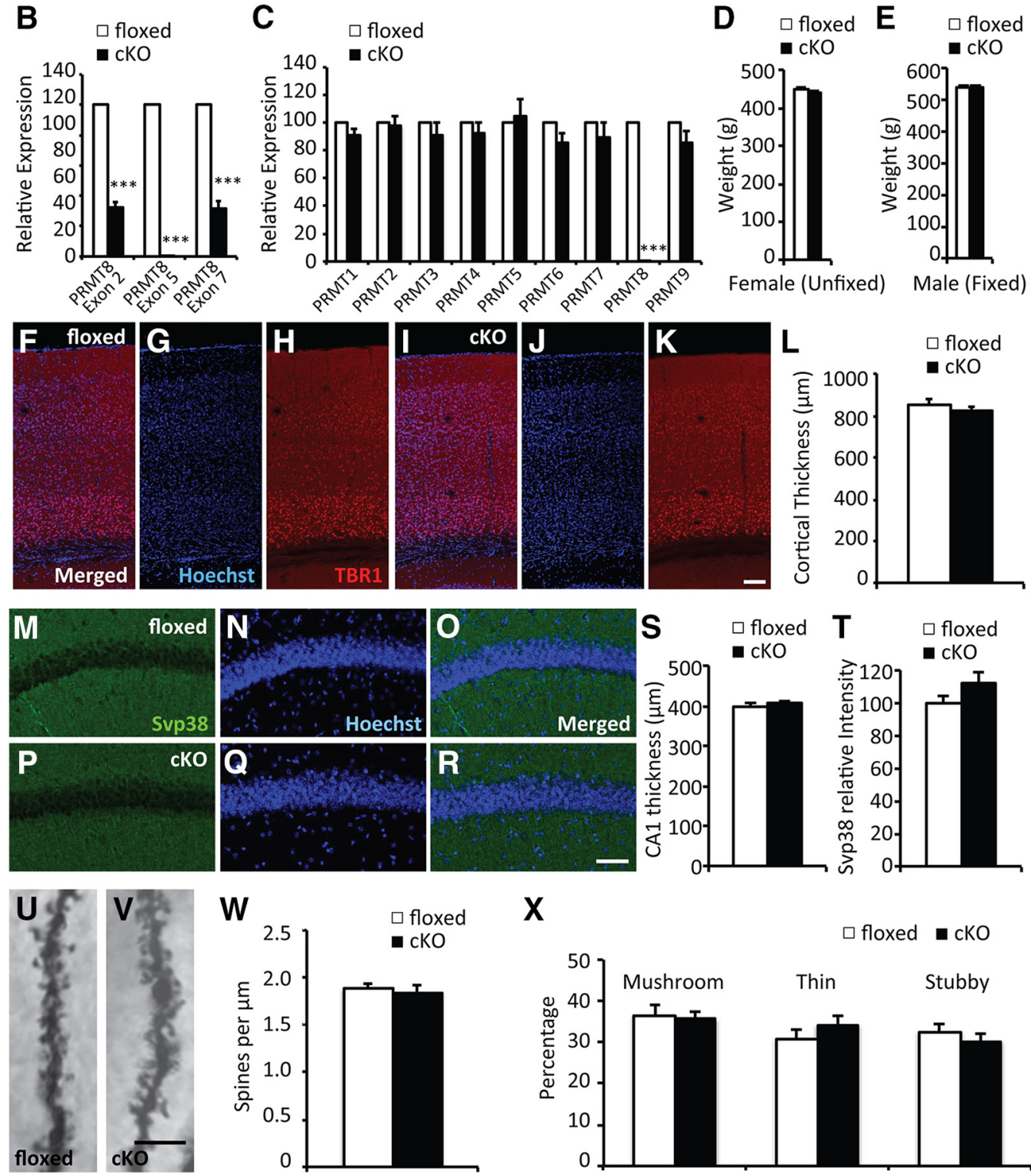

$\mathbf{X}$

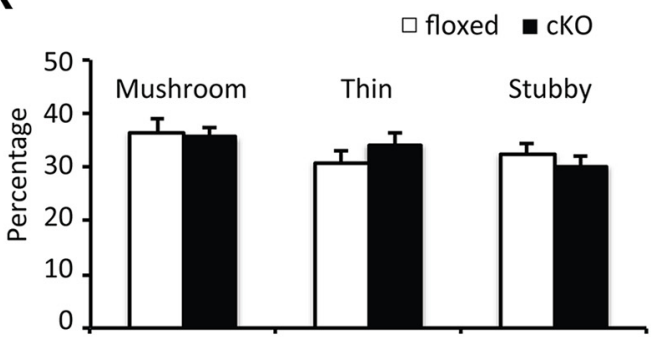

Figure 2. Brain development in Prmt8 cK0 mice. A, Schematic of the Prmt8 transcript indicating the locations of important domains and residues of the encoded protein. Blue boxes represent exons. Red triangles represent the location of loxP sites mediating conditional deletion of exon 5 . N-myristoyl indicates the glycine residue that can be N-myristoylated for membrane targeting. SH3 binding indicates residues involved in interactions with SRChomology 3 domains. SAM binding indicates S-adenosyl methionine binding residues. B, qPCR from hippocampal mRNA of control (Prmt8 floxed) and cKO (Prmt8 floxed; Nestin-cre) mice using primers specific to the indicated Prmt8 exons. $N=3$ for each. C, qPCR from hippocampal mRNA of control and cKO mice using primers specific to each PRMT family member. $N=4$ for each. $\boldsymbol{D}$, Brain weights of female mice measured following dissection of unfixed tissue. $N=8$ for each. $\boldsymbol{E}$, Brain weights of male mice measured following perfusion and dissection of fixed brains. $N=6$ for each. $\boldsymbol{F}-\boldsymbol{K}$, Immunostaining of cortical slices stained with Hoechst and the deep layer cortical marker TBR1. L, Quantification of cortical thickness above hippocampal area CA1. $N=9$ for each. Scale bar, $100 \mu \mathrm{m} . \boldsymbol{M}-\boldsymbol{R}$, Immunostaining of hippocampal area CA1 of mice stained with Hoechst and synaptophysin (Svp38). Scale bar, $50 \mu \mathrm{m}$. $S$, Quantification of the thickness of hippocampal area CA1. $N=8$ and $N=9$, respectively. $T$, Quantification of the synaptophysin staining intensity in hippocampal area CA1. $N=8$ and $N=9$, respectively. $\boldsymbol{U}, \boldsymbol{V}$, Images of Golgi-stained pyramidal neurons from hippocampal area CA1. Scale bar, $5 \mu \mathrm{m}$. $\boldsymbol{W}$, Quantification of the density of all dendritic spines corresponding to $\boldsymbol{U}$ and $\boldsymbol{V}$. $N=$ 18 for each. $\boldsymbol{X}$, Quantification of the proportion of mushroom, thin, or stubby dendritic spines corresponding to $\boldsymbol{U}$ and $\boldsymbol{V} . \boldsymbol{N}=18$ for each. ${ }^{* * *} p<0.001$ (Student's t test). Error bars indicate SEM.

PRMT8 post-transcriptionally regulates synaptic proteins Given the effects we observed following Prmt8 mutation on synaptic function and plasticity, we next sought to test whether synaptic protein composition was altered in Prmt8 cKO mice. To address this possibility, we examined the levels of a panel of presynaptic and postsynaptic proteins both in hippocampal lysates from Prmt8 cKO mice and controls, as well as in synaptosomal preparations from these mice. We found no change in the synaptic levels of the voltage-gated calcium channel subunit Cacna1C, which we were unable to detect in total lysates (Fig. 5A). Similarly, we found no differences in the total or synaptic levels of the synaptic vesicle proteins Synapsin 1 (Syn1), Synapsin 2 (Syn2), Synapsin 3 (Syn3), and Synaptophysin (Svp38), or the presynaptic regulators $N$-ethylmaleimide-sensitive factor (Nsf-1), Synap- 
A
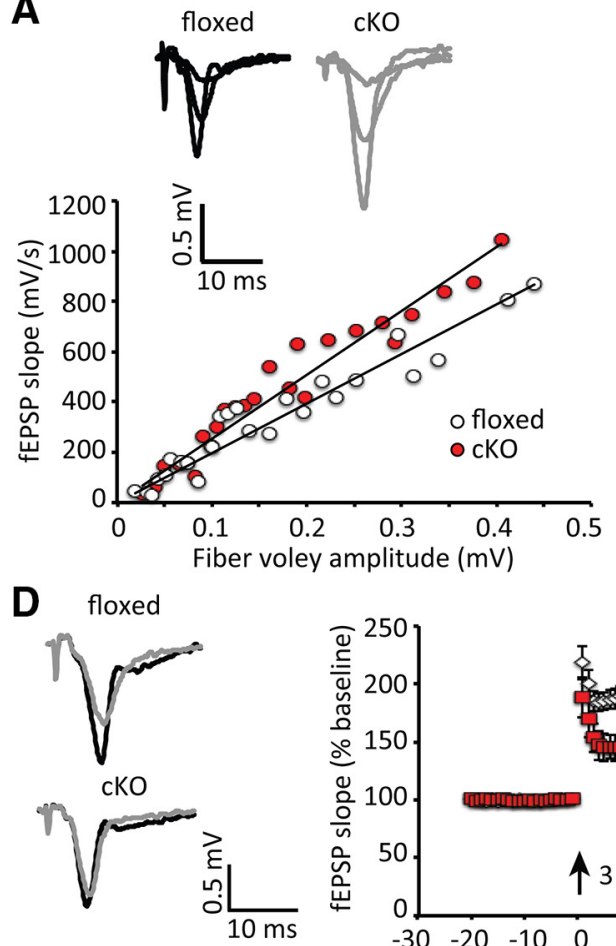

B

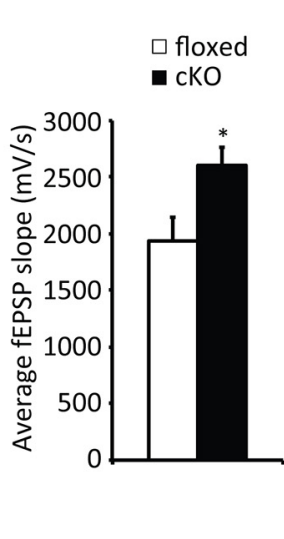

C
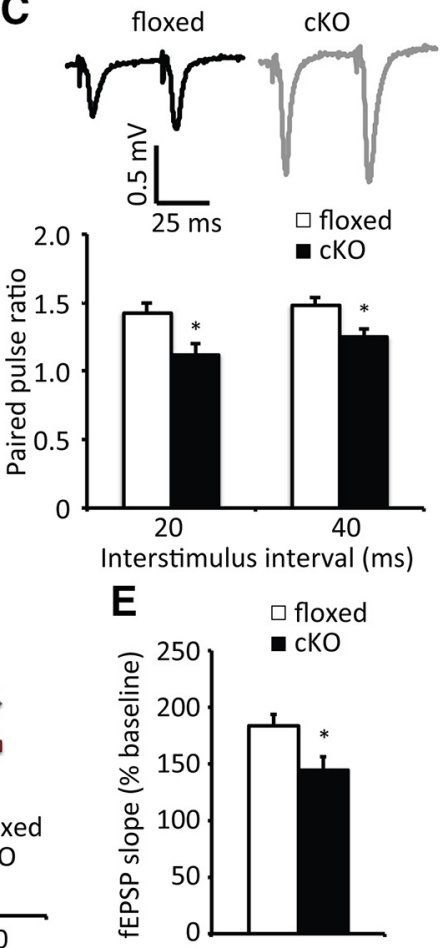

Figure 3. Electrophysiological function is altered in Prmt8 cKO mice. A, Traces and input-output curves from control and Prmt8 cK0 mice derived by plotting the slopes of evoked fEPSPs against fiber-volley amplitude. $\boldsymbol{B}$, Quantification of fEPSP slopes. $N=9$ for each. $\boldsymbol{C}$, Traces and PPF ratios at the indicated interstimulus intervals. $N=9$ and $N=11$, respectively. $\boldsymbol{D}, \mathrm{LTP}$ induced by $3 \times$ TBS in slices from control and Prmt8 cKO mice. Sample traces represent fEPSP at $1 \mathrm{~min}$ before (gray) and $1 \mathrm{~h}$ after (black) TBS. E, Quantification of LTP induction as a percentage of baseline transmission from 50 to 60 min after $3 \times$ TBS. $N=7$ and $N=10$ for control and cKO. ${ }^{*} p<0.05$ (Student's t test). Error bars indicate SEM.

totagmin 7 (Syt7), Synaptotagmin 12 (Syt12), and Complexin 1 (Cplx1) when comparing control with cKO mice (Fig. 5A). We next examined a number of glutamate receptor subunits and signaling proteins, finding no change in levels of the AMPA receptor subunits GluA1 and GluA2, the NMDA receptor subunits GluN1 and GluN2B, or the synaptic signaling molecule CaMKII, in either total or synaptosomal lysates (Fig. 5B). In contrast, we did find a significant reduction in levels of the NMDA receptor subunit GluN2A in both total lysates and synaptic fractions (Fig. 5B), suggesting that NMDA receptor function could be altered in Prmt $8 \mathrm{cKO}$ mice. We next examined a number of synaptic and cellular scaffolding proteins, finding no significant change in the total or synaptosomal levels of cytoskeletal component $\alpha$-tubulin or the synaptic scaffolding proteins Shank 1, PSD95, and Homer (Fig. 5C). We also examined levels of the RNA binding protein FMRP and number of cap-dependent translation regulators as these proteins are important for synaptic plasticity, and many are arginine methylated in the mouse brain (Guo et al., 2014), suggesting the possibility that they could be regulated by PRMT8. Although we did not detect changes in FMRP levels in total or synaptic fractions, we did find reduced levels, or trends to reduced levels, in the eukaryotic initiation factors (eIFs) eIF4G1, eIF4H, and eIF4E in both total and synaptic fractions from Prmt8 cKO mice (Fig. 5D). Thus, a number of synaptic plasticity-related proteins exhibit altered expression following Prmt8 mutation.

We next tested whether the mRNA levels corresponding to a number of synaptic proteins, including those we found reduced at the protein level, were altered in Prmt $8 \mathrm{cKO}$ mice. Consistent with their unaltered protein levels, we found no difference in the expression of mRNAs encoding GluA1, PSD95, or CaMKIIA (Fig. 5E). Intriguingly, we also found no difference in the expression of mRNAs encoding GluN2A, eIF4G1, eIF4H, and eIF4E, despite their reduced protein levels in Prmt8 cKO mice (Fig. 5E). We further examined the mRNA levels of cFos, Npas4, and Egr1, three immediate early genes important for synaptic plasticity, and again found no significant difference between cKO versus control mice (Fig. 5E). Thus, we did not detect any differences in the transcript levels of numerous proteins involved in synaptic function and plasticity. Importantly, the discordance of mRNA and protein levels for GluN2A, eIF4G1, eIF4H, and eIF4E indicates that post-transcriptional mechanisms appear to be involved in the reduced levels of these proteins following mutation of Prmt8.

mRNA transport to synaptic sites and localized mRNA translation are important mechanisms in synaptic plasticity (Holt and Schuman, 2013). PRMT8 can physically interact with a number of RNA binding proteins, and numerous RNA binding proteins, such as FMRP, are arginine methylated in the mouse brain (Pahlich et al., 2008; Guo et al., 2014). Thus, we sought to test whether synaptic mRNA localization could be altered in Prmt $8 \mathrm{cKO}$ mice. To test this, we isolated mRNA from hippocampal synaptosomal preparations and compared enrichment of specific mRNAs in these samples with total hippocampal mRNA from the same animals. Using equivalent amounts of total and synaptosomal RNA, we found that, as expected, GAPDH and histone $H 2 A$ mRNAs were depleted in synaptic samples versus total RNA ( $54 \pm 2 \%$ and $63 \pm 6 \%$, respectively). In contrast, known synaptically localized mRNAs, such as PSD95, Arc (encoding Activity-regulated cytoskeletal protein), and CaMKII (Burgin et al., 1990; Steward et al., 1998; Zalfa et al., 2007), were enriched in synaptic versus total mRNA ( $147 \pm 23 \%, 207 \pm 16 \%$, and $212 \pm 16 \%$, respectively). Next, we compared the synaptic enrichment, normalized to GAPDH, of these and other transcripts from control and Prmt8 cKO mice (Fig. $5 F$ ). We found no difference in the synaptic en- 
A

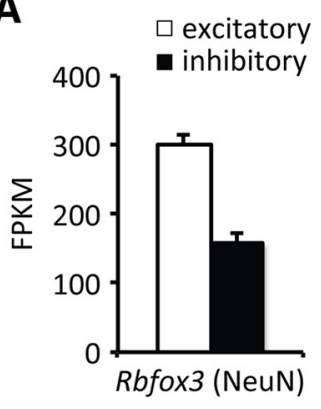

E

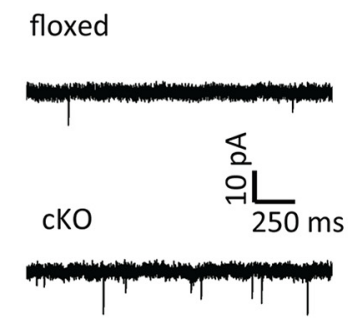

J

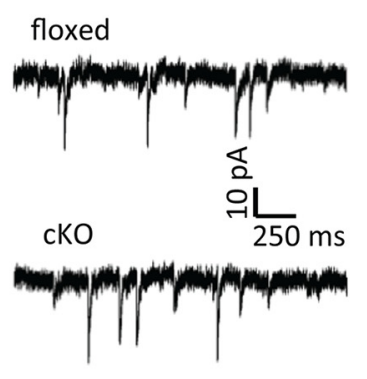

B

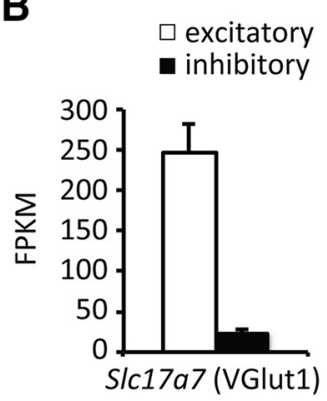

F
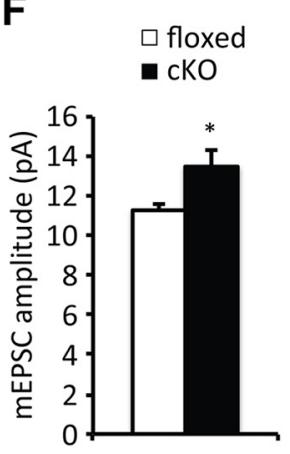

K

$$
\begin{aligned}
& \square \text { floxed } \\
& \text { - cKO }
\end{aligned}
$$

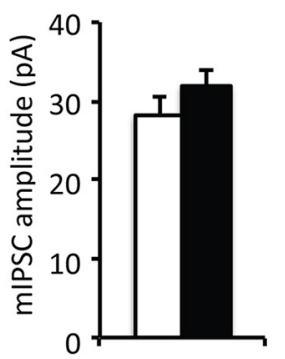

C

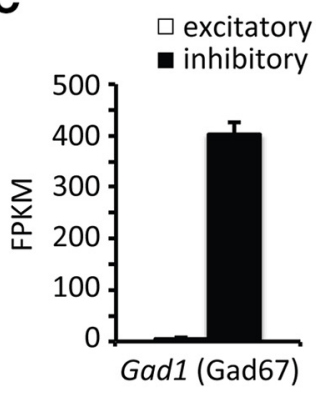

D

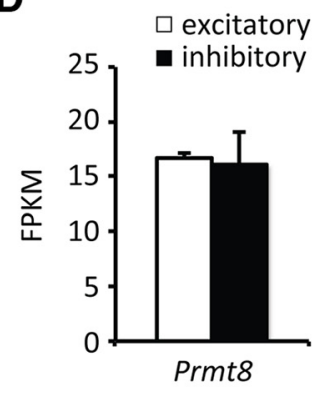

G

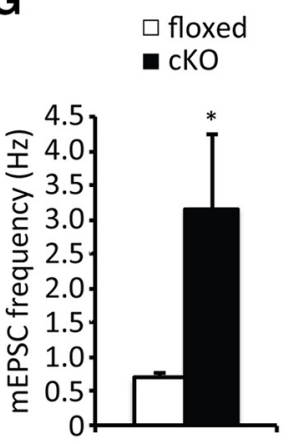

L

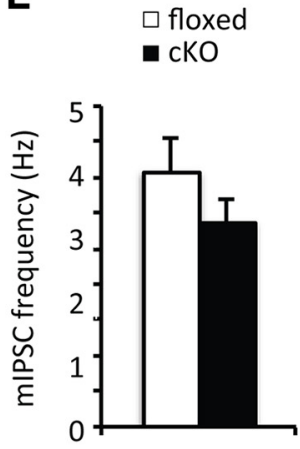

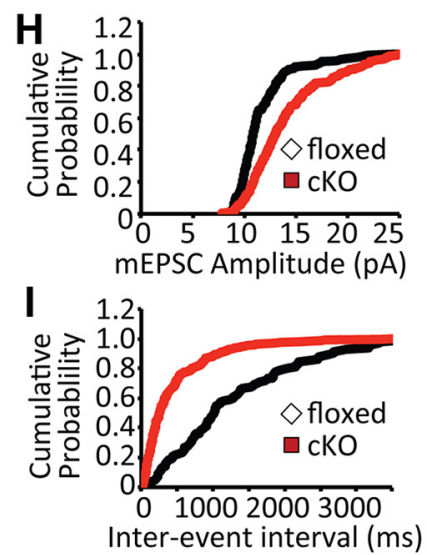
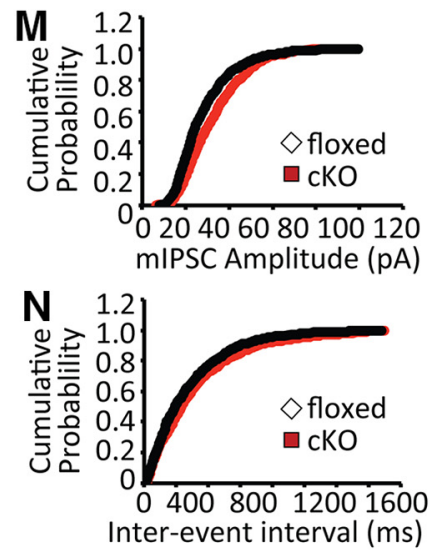

Figure 4. Prmt8 mutation alters mEPSC, but not mIPSC, properties. FPKM (Fragments Per Kilobase of transcript per Million mapped reads) values for (A) Rbfox3 (NeuN), (B) S/c17a7 (VGlut1), (C) Gad1 (Gad67), and (D) Prmt8 from sorted mouse cortical excitatory and inhibitory neurons (based on Mo et al., 2015). $\boldsymbol{E}$, Traces of mEPSC activity from intracellular recordings of pyramidal neurons. $\boldsymbol{F}$, Quantification of average mEPSC amplitudes and $(\boldsymbol{H})$ cumulative probability curves from control and cKO slices. $N=9$ and $N=8$, respectively. $\boldsymbol{G}$, Quantification of average $m E$ EPSC frequency and $(\boldsymbol{I})$ cumulative probability curves of interevent intervals from control and cKO slices. $N=10$ and $N=8$, respectively. $J$, Traces of mIPSC activity from intracellular recordings of pyramidal neurons. $\boldsymbol{K}$, Quantification of average mIPSC amplitudes and $(\boldsymbol{M})$ cumulative probability curves from control and $\mathrm{KK} 0$ slices. $N=10$ and $N=13$, respectively. $\boldsymbol{L}$, Q Quantification of average mIPSC frequency and $(\boldsymbol{N})$ cumulative probability curves of interevent intervals from control and cKO slices. $N=10$ and $N=13$, respectively. ${ }^{*} p<0.05$ (Student's t test). Error bars indicate SEM.

richment of H2A, FMRP, PSD95, Arc, CaMKII, or MAP1B (encoding microtubule-associated protein $1 \mathrm{~B}$ ) mRNAs (Fig. $5 F$ ), suggesting that PRMT8 is not required for proper mRNA localization to synaptic sites.

GluN2A-mediated currents are reduced in PRMT8 cKO mice The reduction in GluN2A protein levels we observed in hippocampal lysates from Prmt8 cKO mice prompted us to test whether we could also detect functional alterations in NMDAR function. Thus, we measured evoked GluN2A currents in CA1 pyramidal neurons from control and Prmt $8 \mathrm{cKO}$ slices. Consistent with the reduced GluN2A protein levels we observed in Prmt8 mutant hippocampi, GluN2A-mediated NMDAR currents were also strongly reduced compared with controls (Fig. 6A,B). We also calculated the decay time of GluN2A- mediated currents from control and cKO mice. Although we found a trend toward increased decay time of GluN2A-mediated currents from Prmt8 cKO slices, it was not significantly different from controls, suggesting that the main effect may be due to reduced GluN2A levels rather than altered kinetics (Fig. 6C).

PRMT8 cKO mice exhibit deficits in contextual fear memory Finally, we undertook a behavioral analysis of Prmt $8 \mathrm{cKO}$ mice to examine the potential effects on cognitive processes that might arise from the synaptic protein and synaptic functional defects that we uncovered in these mice. We found no difference between control and $\mathrm{cKO}$ mice in total distance traveled in the open field arena (Fig. 7A). Similarly, we observed no significant differences in the proportions of time control and $\mathrm{cKO}$ mice spent in the center versus periphery of the open field arena, suggesting that 
A Presynaptic and vesicle associated proteins

\begin{tabular}{|c|c|c|}
\hline Total lysate & \multicolumn{2}{|l|}{ Synaptosomal } \\
\hline cKO/flox & cKO/flox & Protein \\
\hline 240 - not detectable & $=1.05$ & Cacna1C \\
\hline $80-=1.00$ & $=0.97$ & Syn1 \\
\hline $75-=0.96$ & $=0.99$ & Nsf-1 \\
\hline $65-\longrightarrow 0.92$ & $=0.97$ & Syn2 \\
\hline $60-\cdots 1.03$ & $=1.08$ & Syn3 \\
\hline $55-\cdots 0.90$ & $=0.95$ & Syt7 \\
\hline $45-\longrightarrow 0.95$ & $=0.97$ & Syt12 \\
\hline $38-=0.95$ & 0.98 & Svp38 \\
\hline $20---1.10$ & $=1.00$ & Cplx1 \\
\hline $42-\div-\cdots$ & -1 & Actin \\
\hline flox cKO & flox cKO & \\
\hline
\end{tabular}

B Neurotransmitter receptors and signaling proteins

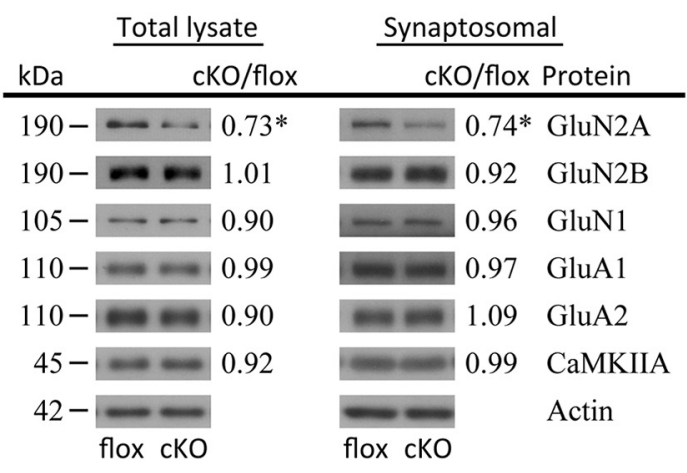

\section{Translation factors and RNA-binding proteins}

\section{Scaffolding and cytoskeletal proteins}

\begin{tabular}{|c|c|c|c|}
\hline \multirow[b]{2}{*}{$\mathrm{kDa}$} & Total lysate & \multicolumn{2}{|c|}{ Synaptosomal } \\
\hline & cKO/flox & cKO/flox & Protein \\
\hline $220-$ & 0.95 & $1+4=0.95$ & Shank1 \\
\hline $95-$ & 0.88 & 0.99 & PSD95 \\
\hline $55-$ & $-=0.96$ & $=-1.02$ & Tubulin \\
\hline $40-$ & $-=0.92$ & $=1.09$ & Homer \\
\hline $42-$ & $--\infty$ & $-\infty$ & Actin \\
\hline
\end{tabular}

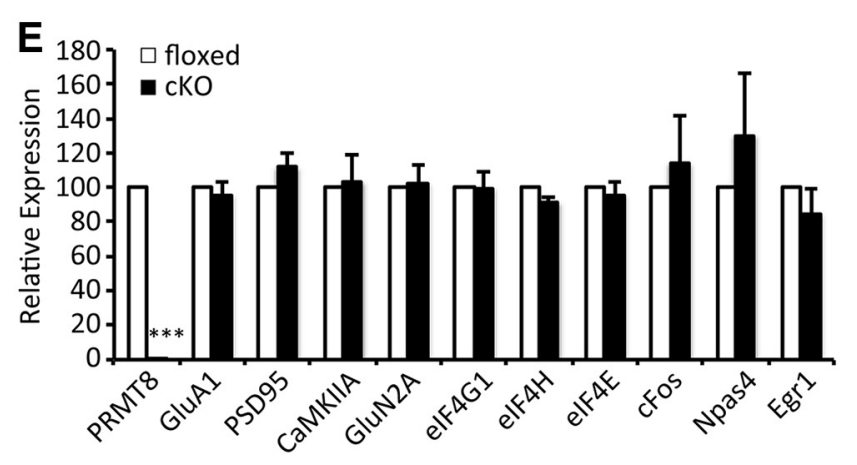

Figure 5. Synaptic protein alterations following mutation of PRMT8. A-D, Western blots from total lysate or synaptosomal preparations from hippocampi of control and Prmt8 cK0 mice probed with antibodies against the indicated proteins. Protein molecular weight as well as the ratio of each protein, normalized to actin, in cKO versus control samples is indicated. $\boldsymbol{A}$, Synaptic vesicle proteins and other regulators of presynaptic function. $\boldsymbol{B}$, Glutamate receptors and the signaling protein CaMKII. C, Cytoskeletal and synaptic scaffolding proteins. D, Translation initiation factors and mRNA binding proteins. $N=4$ for all. $E, q P C R$ for Prmt8 and genes encoding selected synaptic plasticity-related proteins from hippocampal mRNA of control and $c K 0$ mice. $N=3$ for all. $F, q P C R$ comparing the ratio of selected transcripts from synaptic versus total mRNA from control and cK0 hippocampi. The established synaptically localized mRNAs encoding PSD95, Arc, and CaMKII show clear enrichment in synaptic versus total mRNA. $N=3$ for all. ${ }^{*} p<0.05$ (Student's t test). ${ }^{* * *} p<0.001$ (Student's t test). Error bars indicate SEM.
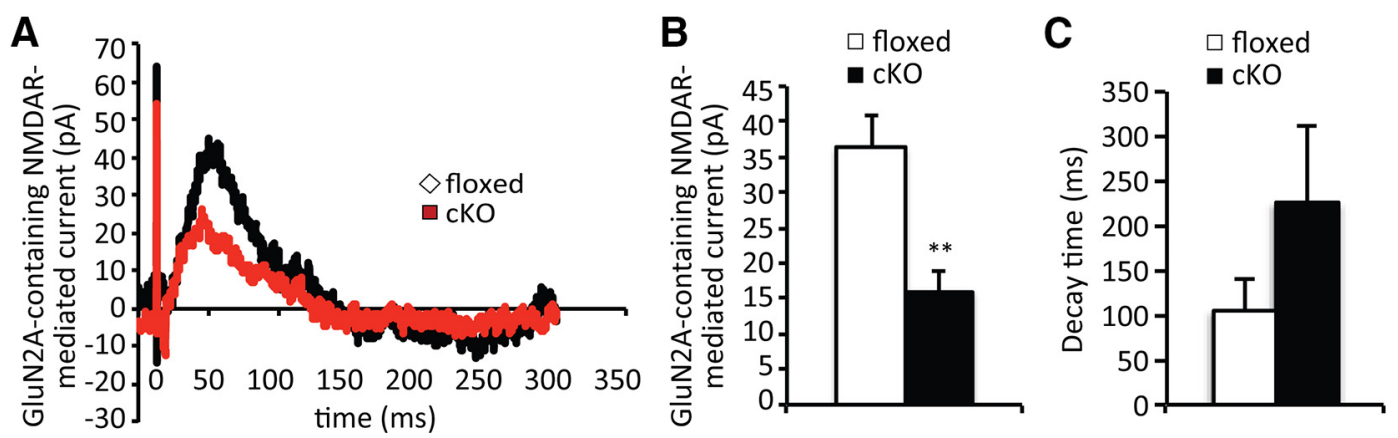

Figure 6. GluN2A currents are reduced in Prmt8 cK0 mice. Traces $(\boldsymbol{A})$ and quantification $(\boldsymbol{B})$ of GluN2A-mediated currents from control and Prmt8 $\mathrm{cKO}$ mice $(N=8$ and $N=7$, respectively). C, Quantification of decay time for GluN2A-mediated currents from control and Prmt 8 cKO mice ( $N=8$ and $N=7$, respectively). ${ }^{* *} p<0.01$ (Student's t test). Error bars indicate SEM. 
A

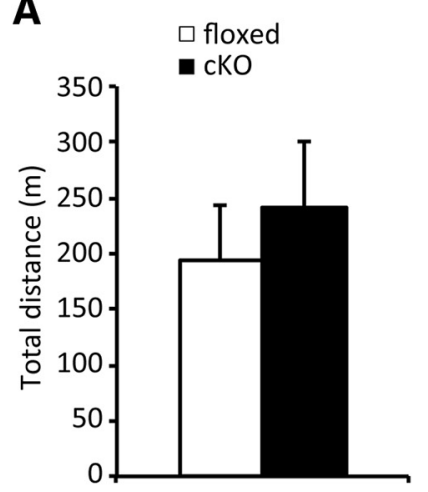

D $\quad \square$ floxed

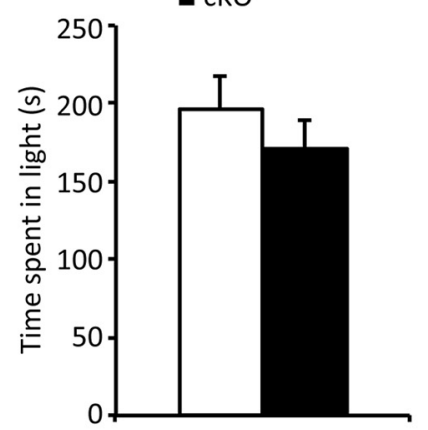

G

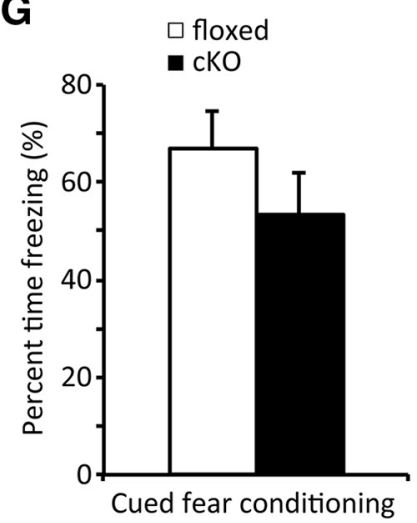

B

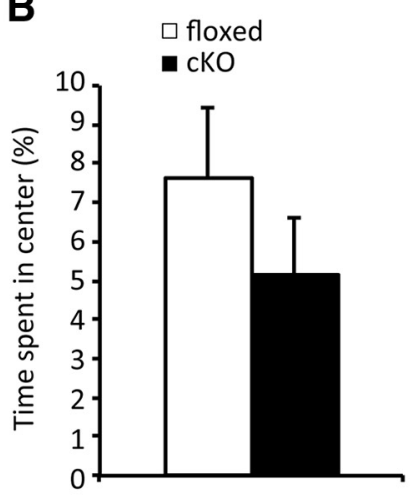

E

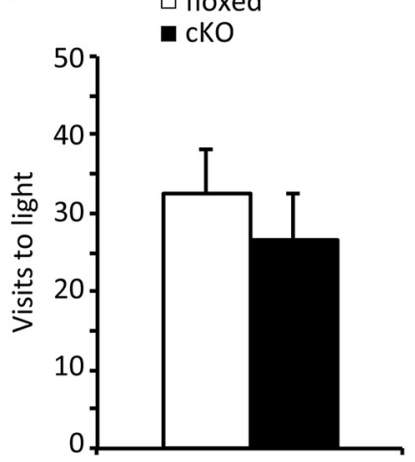

H

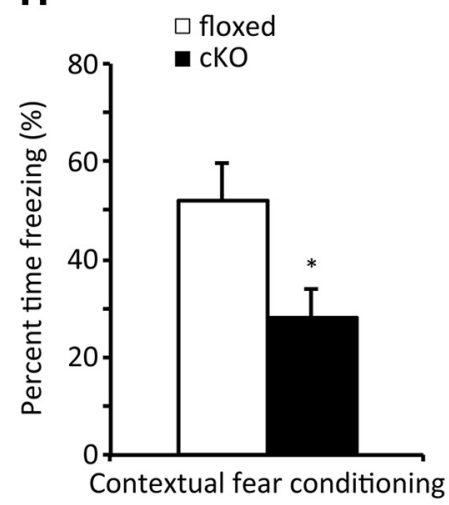

C

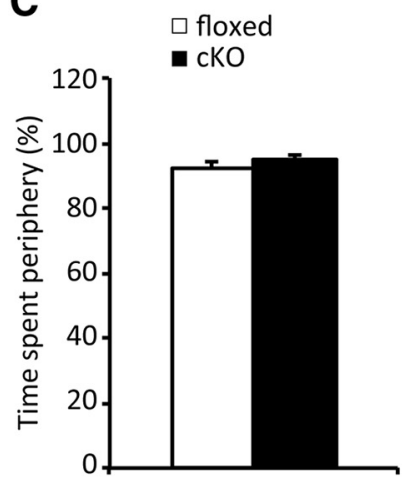

F
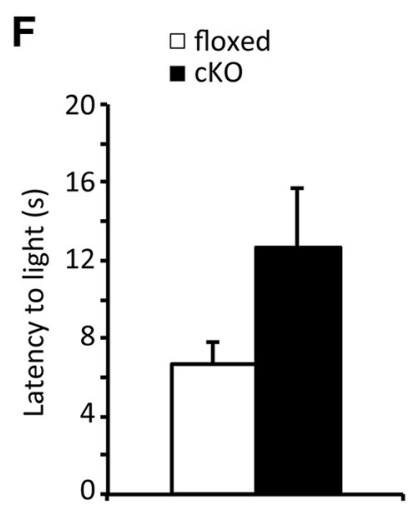

Figure 7. Prmt8 cK0 mice exhibit impaired fear memory. $\boldsymbol{A}-\boldsymbol{C}$, Activity of control and Prmt8 cKO mice in the open field arena. $\boldsymbol{A}$, Total distance traveled. $\boldsymbol{B}$, Percentage of time spent in center. $\boldsymbol{C}$, Percentage of time spent in the periphery. $N=12$ and $N=11$, respectively, for each parameter. $\boldsymbol{D}-\boldsymbol{F}$, Light-dark test. $\boldsymbol{D}$, Total time spent in light. $\boldsymbol{E}$, Number of visits to the light. $\boldsymbol{F}$, Latency to visit light. $N=11$ and $N=10$, respectively, for each parameter. Percentage of time spent freezing during probe tests following cued $(\boldsymbol{G})$ and contextual $(\boldsymbol{H})$ fear conditioning of control and cKO mice. $N=11$ and $N=10$, respectively, for each test. ${ }^{*} p<0.05$ (Student's t test). Error bars indicate SEM.

anxiety-related behaviors were not altered by Prmt 8 mutation (Fig. $7 \mathrm{~B}, \mathrm{C}$ ). Also consistent with normal anxiety-related behaviors, control and cKO mice did not differ in the amount of time spent in light, the number of visits to light, or the latency to visit light in the light/dark test (Fig. $7 D-F$ ). We next assayed fear learning and memory using a classical fear-conditioning paradigm. Mice were habituated to a chamber, and then an audible tone was paired with an aversive foot shock. Typically, mice will learn to associate both the chamber (context) and the tone (cue) with the foot shock. At $24 \mathrm{~h}$ later, the mice were returned to the same chamber, and the percentage of time they spent freezing (without tone or foot shock) was quantified as a measure of context-dependent fear memory. A further $24 \mathrm{~h}$ later, the mice were placed in a distinct chamber and played the tone that was initially paired with foot shock; the percentage of time spent freezing was again quantified, this time as a measure of cued fear memory. These experiments revealed no difference in freezing by Prmt8 cKO mice compared with controls in response to tone (Fig. $7 G$ ), but significantly less freezing by cKO mice when returned to the training chamber (Fig. $7 H$ ). Thus, mutation of Prmt8 results in a specific deficit in contextual fear memory, consistent with altered hippocampal function.

\section{Discussion}

Here we have established that PRMT8 is a synaptic protein, and characterized hippocampal synaptic structures, protein content, and electrophysiological function, as well as examining behavioral function in Prmt $8 \mathrm{cKO}$ mice. We find that, although synapse and dendritic spine density are unaltered, mutation of Prmt8 does affect multiple measures of neuronal function, synaptic protein composition, and hippocampal-dependent fear learning. 
These findings clearly demonstrate that PRMT8 is required for normal hippocampal function of the mammalian brain.

Our most striking findings were that multiple excitatory synaptic functional parameters were altered by Prmt 8 mutation. Input-output curves of field potentials following stimulation of Schaffer collaterals indicated an increase in baseline synaptic transmission in Prmt $8 \mathrm{cKO}$ slices. Consistently, PPF ratios were reduced in slices from cKO mice. In addition, intracellular recordings revealed an elevation in both mEPSC amplitudes and frequencies, perhaps underlying the increased baseline synaptic function we observed. We furthermore observed deficits in GluN2A-mediated NMDAR currents in Prmt $8 \mathrm{cKO}$ slices. In contrast, we found that mIPSC properties were not altered by Prmt 8 mutation, indicating that PRMT8 has distinct effects in different neuronal subtypes.

The large increase we observed in MEPSC frequencies was surprising considering that synapse density (as assayed by synaptophysin staining) and dendritic spine density were both unaltered in Prmt $8 \mathrm{cKO}$ mice. Together, these observations suggest an alteration in the synaptic vesicle release machinery in cKO mice, although we did not detect any differences in proteins involved in presynaptic release in our synaptic protein analysis. Similarly, we did not detect any increases in AMPA receptor proteins that would be consistent with elevated mEPSC amplitudes in Prmt8 cKO mice. In conjunction with these alterations in synaptic function, we also observed reduced LTP induction in cKO mice. It is possible that elevated baseline transmission in the $\mathrm{CKO}$ mice partially occludes LTP induction; however, other mechanisms, such as the impaired NMDAR signaling we observe, could also result in defective long-term synaptic plasticity following Prmt8 mutation. Further experiments will be required to distinguish between these possibilities. Regardless, multiple aspects of presynaptic and postsynaptic excitatory function are affected in mice lacking functional PRMT8 protein.

In addition to reduced GluN2A levels, we also observed reductions in multiple members (eIF4E, eIF4G1, and eIF4H) of the mRNA cap binding complex, required for translation of most mRNAs in eukaryotic cells (Sonenberg and Hinnebusch, 2009). Despite the requirement of this protein complex for global cellular protein synthesis, alterations in cap binding complex activity are an important regulator of synaptic function, plasticity, and behavior (Banko et al., 2005; Penney et al., 2012; Gkogkas et al., 2013). Importantly, changes in cap binding complex function can selectively affect certain mRNAs based on sequences or structural elements in their untranslated regions (Sonenberg and Hinnebusch, 2009). Furthermore, ribosomes, cap binding complex proteins, and specific mRNAs also localize to postsynaptic sites in the nervous system, allowing for rapid, activity-dependent translation of key synaptic proteins (Holt and Schuman, 2013). Together, these mechanisms can allow modest and/or localized changes in cap binding complex function to affect synaptic plasticity but not global protein synthesis. Intriguingly, the GluN2A mRNA has been shown to possess upstream open reading frames and secondary structure elements in its $5^{\prime}$ UTR that inhibit translation of the protein coding open reading frame (Wood et al., 1996). Thus, it is possible that the observed decrease in GluN2A protein could be due to inefficient translation resulting from reduced cap binding complex function in Prmt8 cKO mice, although this idea requires direct testing. The observed reduction in cap binding complex proteins could also affect synaptic function and plasticity in cKO mice via additional target mRNAs, as well as by potentially inhibiting activity-induced synaptic protein synthesis.
Whether the reduced GluN2A levels and function in Prmt8 cKO mice are due to perturbed translation or other mechanisms, they have the potential to contribute to multiple cellular and behavioral phenotypes we describe in these mice. GluN2Acontaining NMDARs are important modulators of hippocampal LTP, and mice harboring GluN2A mutations have multiple behavioral defects, including impaired contextual fear learning (Sakimura et al., 1995; Sprengel et al., 1998). Thus, despite unaltered levels of GluN1 and GluN2B, reduced levels of GluN2A in Prmt8 cKO mice may make important contributions to their altered synaptic and cognitive function.

The multiple neuronal function alterations we describe following Prmt 8 mutation are accompanied by a deficit in contextual fear memory, whereas the other behavioral parameters we tested were not significantly different between control and cKO mice. Control and $\mathrm{cKO}$ mice traveled a similar distance in the open field, suggesting no difference in activity levels. This finding is in contrast to Kim et al. (2015), who reported a hyperactivity phenotype in whole-body Prmt8 cKO mice (using the Ayul-cre driver). We used the neural lineage-specific Nestin-cre to conditionally delete Prmt8; however, because Prmt8 is expressed almost exclusively in neurons (Lee et al., 2005; Zhang et al., 2014), it is not clear how use of these different cre drivers would affect locomotor activity. We also did not observe a hindlimb clasping phenotype in cKO mice, as reported by Kim et al. (2015) (and data not shown). Our behavioral analysis further examined anxietyrelated phenotypes in Prmt8 cKO mice, indicating that Prmt8 mutation does not appear to alter anxiety-related behaviors. Finally, we tested both cued and context-dependent fear memory in cKO mice and controls. Although we did not observe significantly reduced freezing behavior in response to a cue associated with foot shock, we did find that Prmt $8 \mathrm{cKO}$ mice froze less in the training context that was associated with foot shock. As contextual fear learning is a hippocampal-dependent process, these results are consistent with a deficit in hippocampal cognitive function following mutation of Prmt8.

In the current study, we focused on phenotypes in hippocampal pyramidal neurons resulting from Prmt8 mutation; however, PRMT8 has been reported to affect other neuron types and brain regions as well. Kim et al. (2015) reported that Prmt8 mutation impaired cerebellar Purkinje neuron branching, as well as reducing the levels of choline and acetylcholine in the cerebellum. In addition, Lee et al. (2017) found that Prmt8 mutation increased perineuronal net formation around parvalbumin-positive interneurons of the visual cortex, associated with increased parvalbumin neuron complexity and reduced visual acuity. Thus, it is possible that altered cholinergic or GABAergic function in Prmt8 cKO mouse brains could contribute to the defects in hippocampal synaptic plasticity and behavior we describe here. Further experiments will be required to test these possibilities.

PRMT8 is a multifunctional protein possessing both arginine methyltransferase and phospholipase activities (Lee et al., 2005; Kim et al., 2015). The relative contribution of these enzymatic functions to Prmt8 cKO phenotypes remains an open question. Whereas few endogenous PRMT8 methylation targets have been identified, many synaptic proteins are arginine methylated in the mouse brain (Guo et al., 2014). These include a number of proteins examined in our analysis (Syn1, Syn3, Syt7, eIF4G1, eIF4H, and FMRP); however, determining whether PRMT8 regulates the methylation of these proteins, and what effects that methylation would have on protein function, will require further analysis. It is interesting to note that multiple members of the mRNA cap binding complex, whose levels we found reduced in Prmt8 
cKO mice, are methylation targets. Potentially, arginine methylation of these proteins could regulate their stability or otherwise regulate the formation and/or function of the cap binding complex. Also noteworthy was our observation that only a minority of tagged PRMT8 protein localized to the nucleus. Multiple PRMT enzymes are well-characterized epigenetic regulators of gene expression (Bedford and Clarke, 2009), and some studies have implicated PRMT8 in similar mechanisms (Kousaka et al., 2009; Simandi et al., 2015; Lee et al., 2017). Our observation that the proteins we found reduced in Prmt8 cKO mice did not exhibit parallel reductions in their mRNA levels, and that PRMT8 itself localizes to synaptic sites, suggest that PRMT8 likely plays important non-nuclear roles in neurons, although we do not rule out additional nuclear functions for PRMT8.

PRMT8-dependent phospholipase D activity could also regulate brain function in multiple ways. Phospholipase D enzymes catalyze the conversion of phosphatidylcholine into phosphatidic acid and choline, with the latter serving as the substrate for acetylcholine metabolism (Klein, 2005). As noted, Prmt8 knock-out mice were reported to have reduced cerebellar choline and acetylcholine levels, as well as increased phosphatidylcholine content (Kim et al., 2015). Alterations of both cholinergic neurotransmission and the catabolism of phosphatidylcholine, a major phospholipid component of biological membranes, have the potential to affect hippocampal function. Thus, the methyltransferase and phospholipase activities of PRMT8 may synergistically contribute to the phenotypes of Prmt $8 \mathrm{cKO}$ mice.

Together, our findings establish PRMT8 as a constituent of the synaptic proteome with important roles in the nervous system. PRMT8 post-transcriptionally modulates the levels of a number of proteins important for synaptic plasticity, and Prmt8 cKO mice exhibit multiple alterations in hippocampal synaptic function and plasticity. These alterations in synaptic function occur without detectable changes in brain or neuron morphology and are accompanied by impairment in hippocampal-dependent fear memory. Our findings establish PRMT8 as an important component of the molecular machinery regulating synaptic physiology and reveal novel roles for this protein in hippocampal function.

\section{References}

Allen Institute for Brain Science (2011) Mouse reference atlas, Version 2. mouse.brain-map.org.

Banko JL, Poulin F, Hou L, DeMaria CT, Sonenberg N, Klann E (2005) The translation repressor 4E-BP2 is critical for eIF4F complex formation, synaptic plasticity, and memory in the hippocampus. J Neurosci 25:95819590. CrossRef Medline

Bedford MT, Clarke SG (2009) Protein arginine methylation in mammals: who, what, and why. Mol Cell 33:1-13. CrossRef Medline

Burgin KE, Waxham MN, Rickling S, Westgate SA, Mobley WC, Kelly PT (1990) In situ hybridization histochemistry of $\mathrm{Ca}^{2+} /$ calmodulindependent protein kinase in developing rat brain. J Neurosci 10:17881798. Medline

Burkhardt U, Stegner D, Hattingen E, Beyer S, Nieswandt B, Klein J (2014) Impaired brain development and reduced cognitive function in phospholipase D-deficient mice. Neurosci Lett 572:48-52. CrossRef Medline

Cathala L, Holderith NB, Nusser Z, DiGregorio DA, Cull-Candy SG (2005) Changes in synaptic structure underlie the developmental speeding of AMPA receptor-mediated EPSCs. Nat Neurosci 8:1310-1318. CrossRef Medline

Chao HW, Tsai LY, Lu YL, Lin PY, Huang WH, Chou HJ, Lu WH, Lin HC, Lee PT, Huang YS (2013) Deletion of CPEB3 enhances hippocampusdependent memory via increasing expressions of PSD95 and NMDA receptors. J Neurosci 33:17008-17022. CrossRef Medline

Gkogkas CG, Khoutorsky A, Ran I, Rampakakis E, Nevarko T, Weatherill DB, Vasuta C, Yee S, Truitt M, Dallaire P, Major F, Lasko P, Ruggero D, Nader
K, Lacaille JC, Sonenberg N (2013) Autism-related deficits via dysregulated eIF4E-dependent translational control. Nature 493:371-377. CrossRef Medline

Guo A, Gu H, Zhou J, Mulhern D, Wang Y, Lee KA, Yang V, Aguiar M, Kornhauser J, Jia X, Ren J, Beausoleil SA, Silva JC, Vemulapalli V, Bedford MT, Comb MJ (2014) Immunoaffinity enrichment and mass spectrometry analysis of protein methylation. Mol Cell Proteomics 13:372-387. CrossRef Medline

Holt CE, Schuman EM (2013) The central dogma decentralized: new perspectives on RNA function and local translation in neurons. Neuron 80: 648-657. CrossRef Medline

Kandel ER (2001) The molecular biology of memory storage: a dialogue between genes and synapses. Science 294:1030-1038. CrossRef Medline

Kim JD, Park KE, Ishida J, Kako K, Hamada J, Kani S, Takeuchi M, Namiki K, Fukui H, Fukuhara S, Hibi M, Kobayashi M, Kanaho Y, Kasuya Y, Mochizuki N, Fukamizu A (2015) PRMT8 as a phospholipase regulates Purkinje cell dendritic arborization and motor coordination. Sci Adv 1:e1500615. CrossRef Medline

Klein J (2005) Functions and pathophysiological roles of phospholipase D in the brain. J Neurochem 94:1473-1487. CrossRef Medline

Kousaka A, Mori Y, Koyama Y, Taneda T, Miyata S, Tohyama M (2009) The distribution and characterization of endogenous protein arginine $\mathrm{N}$-methyltransferase 8 in mouse CNS. Neuroscience 163:1146-1157. CrossRef Medline

Lee J, Sayegh J, Daniel J, Clarke S, Bedford MT (2005) PRMT8, a new membrane-bound tissue-specific member of the protein arginine methyltransferase family. J Biol Chem 280:32890-32896. CrossRef Medline

Lee PK, Goh WW, Sng JC (2017) Network-based characterization of the synaptic proteome reveals that removal of epigenetic regulator Prmt8 restricts proteins associated with synaptic maturation. J Neurochem 140: 613-628. CrossRef Medline

Lois C, Hong EJ, Pease S, Brown EJ, Baltimore D (2002) Germline transmission and tissue-specific expression of transgenes delivered by lentiviral vectors. Science 295:868-872. CrossRef Medline

Mo A, Mukamel EA, Davis FP, Luo C, Henry GL, Picard S, Urich MA, Nery JR, Sejnowski TJ, Lister R, Eddy SR, Ecker JR, Nathans J (2015) Epigenomic signatures of neuronal diversity in the mammalian brain. Neuron 86:1369-1384. CrossRef Medline

Pahlich S, Zakaryan RP, Gehring H (2008) Identification of proteins interacting with protein arginine methyltransferase 8: the Ewing sarcoma (EWS) protein binds independent of its methylation state. Proteins 72: 1125-1137. CrossRef Medline

Penney J, Tsurudome K, Liao EH, Elazzouzi F, Livingstone M, Gonzalez M, Sonenberg N, Haghighi AP (2012) TOR is required for the retrograde regulation of synaptic homeostasis at the Drosophila neuromuscular junction. Neuron 74:166-178. CrossRef Medline

Sakimura K, Kutsuwada T, Ito I, Manabe T, Takayama C, Kushiya E, Yagi T, Aizawa S, Inoue Y, Sugiyama H (1995) Reduced hippocampal LTP and spatial learning in mice lacking NMDA receptor epsilon 1 subunit. Nature 373:151-155. CrossRef Medline

Seo J, Giusti-Rodríguez P, Zhou Y, Rudenko A, Cho S, Ota KT, Park C, Patzke H, Madabhushi R, Pan L, Mungenast AE, Guan JS, Delalle I, Tsai LH (2014) Activity-dependent p25 generation regulates synaptic plasticity and Abeta-induced cognitive impairment. Cell 157:486-498. CrossRef Medline

Simandi Z, Czipa E, Horvath A, Koszeghy A, Bordas C, Póliska S, Juhász I, Imre L, Szabó G, Dezso B, Barta E, Sauer S, Karolyi K, Kovacs I, Hutóczki G, Bognár L, Klekner Á, Szucs P, Bálint BL, Nagy L (2015) PRMT1 and PRMT8 regulate retinoic acid-dependent neuronal differentiation with implications to neuropathology. Stem Cells 33:726-741. CrossRef Medline

Skarnes WC, Rosen B, West AP, Koutsourakis M, Bushell W, Iyer V, Mujica AO, Thomas M, Harrow J, Cox T, Jackson D, Severin J, Biggs P, Fu J, Nefedov M, de Jong PJ, Stewart AF, Bradley A (2011) A conditional knockout resource for the genome-wide study of mouse gene function. Nature 474:337-342. CrossRef Medline

Sonenberg N, Hinnebusch AG (2009) Regulation of translation initiation in eukaryotes: mechanisms and biological targets. Cell 136:731-745. CrossRef Medline

Sprengel R, Suchanek B, Amico C, Brusa R, Burnashev N, Rozov A, Hvalby O, Jensen V, Paulsen O, Andersen P, Kim JJ, Thompson RF, Sun W, Webster LC, Grant SG, Eilers J, Konnerth A, Li J, McNamara JO, Seeburg PH 
(1998) Importance of the intracellular domain of NR2 subunits for NMDA receptor function in vivo. Cell 92:279-289. CrossRef Medline

Steward O, Wallace CS, Lyford GL, Worley PF (1998) Synaptic activation causes the mRNA for the IEG Arc to localize selectively near activated postsynaptic sites on dendrites. Neuron 21:741-751. CrossRef Medline

Su SC, Seo J, Pan JQ, Samuels BA, Rudenko A, Ericsson M, Neve RL, Yue DT, Tsai LH (2012) Regulation of N-type voltage-gated calcium channels and presynaptic function by cyclin-dependent kinase 5 . Neuron 75:675687. CrossRef Medline

Taneda T, Miyata S, Kousaka A, Inoue K, Koyama Y, Mori Y, Tohyama M (2007) Specific regional distribution of protein arginine methyltransferase 8 (PRMT8) in the mouse brain. Brain Res 1155:1-9. CrossRef Medline

Tronche F, Kellendonk C, Kretz O, Gass P, Anlag K, Orban PC, Bock R, Klein R, Schütz G (1999) Disruption of the glucocorticoid receptor gene in the nervous system results in reduced anxiety. Nat Genet 23:99-103. CrossRef Medline
Vooijs M, van der Valk M, te Riele H, Berns A (1998) Flp-mediated tissuespecific inactivation of the retinoblastoma tumor suppressor gene in the mouse. Oncogene 17:1-12. CrossRef Medline

Wood MW, VanDongen HM, VanDongen AM (1996) The 5'-untranslated region of the N-methyl-D-aspartate receptor NR2A subunit controls efficiency of translation. J Biol Chem 271:8115-8120. CrossRef Medline

Zalfa F, Eleuteri B, Dickson KS, Mercaldo V, De Rubeis S, di Penta A, Tabolacci E, Chiurazzi P, Neri G, Grant SG, Bagni C (2007) A new function for the fragile $\mathrm{X}$ mental retardation protein in regulation of PSD-95 mRNA stability. Nat Neurosci 10:578-587. CrossRef Medline

Zhang Y, Chen K, Sloan SA, Bennett ML, Scholze AR, O'Keeffe S, Phatnani HP, Guarnieri P, Caneda C, Ruderisch N, Deng S, Liddelow SA, Zhang C, Daneman R, Maniatis T, Barres BA, Wu JQ (2014) An RNA-sequencing transcriptome and splicing database of glia, neurons, and vascular cells of the cerebral cortex. J Neurosci 34:11929-11947. CrossRef Medline 